\title{
EDITORIAL
}

\section{Cardiovascular effects of testosterone: implications of the "male menopause"?}

\section{K S Channer, T H Jones}

\section{A relatively low blood concentration of testosterone in the older man may have adverse effects on atherosclerosis, and explain the higher incidence of coronary heart disease in the male}

about twice that observed in the general population. ${ }^{12}$ How may low testosterone contribute to the development of CAD? Hypotestosteronaemia is associated with an atherogenic lipid profile (high low density lipoprotein, low high density lipoprotein, high triglycerides), high fibrinogen and a hypercoaguable state, an increase in insulin resistance and hyperinsulinaemia, and higher systolic and diastolic blood pressure. ${ }^{13}$ In an animal model, castration increased aortic atheroma formation and testosterone replacement ameliorated this effect. ${ }^{14}$ wide differences the ratio of male to female affected individuals remains reasonably constant at more than three to one, ${ }^{1}$ and is not explained by differences in the risk factor profile between the sexes. ${ }^{2}$ The lower incidence of CAD in females is particularly prominent in pre-menopausal women, and increases after the menopause. ${ }^{3}$ This observation spawned the idea that female sex hormones may be protective and that hormone replacement therapy (HRT) may be beneficial. Observational non-randomised epidemiological studies tended to confirm this, ${ }^{4}$ although case controlled studies were less conclusive. ${ }^{5}$ In two published randomised controlled trials, ${ }^{67} \mathrm{com}$ bined oestrogen and progestogen HRT was shown to have no benefit and indeed appeared to have deleterious effects. The influence of sex hormones in the pathophysiology of CAD in men has been relatively ignored. Early studies of oestrogen treatment in men with CAD showed a clear disadvantage. ${ }^{8}$ Epidemiological studies of the blood concentration of total testosterone in men with CAD have failed to consistently demonstrate a role as a risk factor. ${ }^{9}$

\section{TESTOSTERONE PHYSIOLOGY}

The physiology of testosterone is complex. The blood concentration shows a circannual and circadian variation and the biologically active moiety is affected by both the amount of sex hormone binding globulin (SHBG) and albumin. The concept of "bioavailable" testosterone which comprises free testosterone ( $1-2 \%$ of total) and that component loosely bound to albumen (up to about $30 \%$ of total testosterone), has led to more accurate assessment of androgen status. Moreover, because testosterone is converted to oestrogen by the aromatase enzyme in adipose tissue, an individual's concentration is affected by body habitus and weight. There is a higher incidence of men with low testosterone concentrations as age progresses. ${ }^{10}$

Recent studies have shown that men with CAD have significantly lower concentrations of bioavailable testosterone than men with normal coronary angiograms, ${ }^{11}$ and the prevalence of hypogonadism in a population of men with CAD is

\section{VASOACTIVE PROPERTIES OF TESTOSTERONE}

In addition, testosterone has direct vasoactive properties. In animal models of isolated coronary, femoral, and pulmonary arteries testosterone shows a dose dependent vasodilatory effect which is different from that observed with oestrogen because it is independent of an intact endothelium. ${ }^{15}$ It is caused by a direct effect on the vascular smooth muscle, by either an effect on potassium $^{16}$ or calcium channels. ${ }^{17}$ The effect is not meditated by the nuclear androgen receptor because the effect is too rapid and is not reduced by flutamide, a nuclear androgen receptor blocker. Moreover, in a mouse model of testicular feminisation in which the nuclear androgen receptor is absent, testosterone still causes dose dependant vasodilation of femoral arteries. ${ }^{18}$

In man, testosterone has been shown to cause a dose dependant vasodilation both in vitro and in vivo. When testosterone is instilled into the left coronary artery, vasodilation ensues and coronary flow increases. ${ }^{19}$ More importantly, acute administration of intravenous testosterone improves exercise tolerance and reduces angina threshold in men with CAD. ${ }^{20}{ }^{21}$ These effects were observed using supraphysiological doses, but chronic administration of low physiological replacement doses of testosterone over three months in men with chronic stable angina significantly improved exercise tolerance and angina threshold. ${ }^{22}$

The potential concerns of testosterone replacement are prostate cancer and anabolic effects on bone marrow causing an increase in haematocrit. There is currently no evidence that testosterone replacement in hypogonadal men causes an increase in prostate cancer although these studies have been small and retrospective.

Abbreviations: $C A D$, coronary artery disease; HRT; hormone replacement therapy; SHBG, sex hormone binding globulin 
Whether or not the male menopause or andropause exists remains controversial; however, it is evident that the incidence of men with hypogonadism increases as age progresses. A relative low blood concentration of testosterone in the older man may have adverse effects on atherosclerosis and explain the higher incidence of coronary heart disease in the male. Improved formulations of testosterone administration will gradually become available which replace the hormone to physiological concentrations-for example, patches, gels, and buccal release. Longer term studies of HRT for men using these agents are needed to determine whether or not testosterone replacement has beneficial effects on treating coronary heart disease.

\section{Authors' affiliations}

K S Channer, Royal Hallamshire Hospital, Sheffield, UK

T H Jones, Barnsley District General Hospital, Barnsley, and Academic Unit of Endocrinology, Division of Genomic Medicine, University of Sheffield, Sheffield, UK

\section{REFERENCES}

1 Tunstall-Pedoe $\mathbf{H}$, Kuulasmaa K, Mahonen M et al. Contribution of trends in survival and cornary event rate to change in coronary heart disease mortality: 10-year results from 37 WHO MONICA project populations. Lancet 1999;353:1547-57

2 Rayner M, Mockford C, Boaz A. Coronary heart disease statistics. London: British Heart Foundation, 1998.

3 Kalin MF, Zumoff B. Sex hormones and coronary disease: a review of the clinical studies. Steroids 1990;55:330-52

4 Stampfer MJ, Colditz GA, Willett WC, et al. Postmenopausal estrogen therapy and cardiovascular disease. Ten year follow-up from the nurses health study. N Engl J Med 1991;325:756-62.

5 Jick H, Derby LE, Myers MW, et al. Risk of hospital admission for idiopathic venous thromboembolism among users of postmenopausal oestrogens. Lancet 1996;348:981-3

6 Hulley S, Grady D, Bush T, et al, for the HERS Research Group. Randomised trial of estogen plus progestin for secondary prevention of coronary heart disease in postmenopausal women. JAMA 1998;280:605-13.
7 Writing Group for the Womens Health Initiative. Risks and benefits of estrogen plus progestin in healthy postmenopausal women. JAMA 2002;288:321-33

8 Coronary Drug Project Research Group. Initial findings leading to modifications of its research protocol. JAMA 1970;214:1303-13.

9 Alexandersen $\mathbf{P}$, Haarbo J, Christiansen $C$. The relationship of natural androgens to coronary artery disease in males: a review. Atherosclerosis 1996:125:1-13.

10 Vermeulen A, Rubens R, Verdonck L. Testosterone secretion and metabolism in male senescence. J Clin Endocrinol 1972;34:730-5.

11 English KM, Mandour O, Steeds RP, et al. Men with coronary artery disease have lower levels of testosterone than those with normal coronary angiograms. Eur Heart J 2000;21:890-5.

12 Morris P, Pugh PJ, Hall J, et al. The relationship between smoking, statin therapy and testosterone in men with coronary artery disease. Endocrine Abstracts 2002;P248

13 English K, Steeds RP, Jones TH, et al. Testosterone and ischaemic heart disease - is there a link? QJM 1997;90:787-91.

14 Alexandersen P, Haarbo J, Byrjalsen I, et al. Natural androgens inhibit male atherosclerosis. A study of castrated, cholesterol fed rabbits. Circ Res 1999;84:813-9.

15 English KM, Jones RD, Jones TH, et al. Gender differences in the vasomotor effects of different steroid hormones in rat pulmonary and coronary arteries. Horm Metab Res $2001 ; 33: 645-52$.

16 Deenadayalu VP, White RE, Stallone JN, et al. Testosterone relaxes coronary arteries by opening the large-conductance, calcium-activated potassium channel. Am J Physiol 2001;281:H1720-7.

17 English KM, Jones RD, Jones TH, et al. Testosterone acts as a coronary vasodilator by a calcium channel antagonist action. J Endocrinol Invest 2002;25:455-8.

18 Jones RD, Pugh PJ, English KM, et al. Isolated arteries from testicular feminised mice have maintained dilator responses to testosterone but reduced vascular reactivity to acetylcholine. Br J Pharmacol 2001;135: P129.

19 Webb CM, McNeill JG, Hayward CS, et al. Effects of testosterone on coronary vasomotor regulation in men with coronary heart disease. Circulation 1999;100:1690-6.

20 Rosano GMC, Leonardo F, Pagnotta $\mathrm{P}$, et al. Acute anti-ischaemic effect of testosterone in men with coronary artery disease. Circulation 1999:99:1666-70.

21 Webb CM, Adamson DL, de Zeigler D, et al. Effect of acute testosterone on myocardial ischaemia in men with coronary artery disease. Am J Cardiol 1999:83:437-9.

22 English KM, Steeds RP, Diver M, et al. Low dose transdermal testosterone therapy improves angina threshold in men with chronic stable angina. Circulation 2000;102:1906-11.

\section{IMAGES IN CARDIOLOGY.}

\section{Cystic tumour of the atrioventricular node}

A

45 year old asymptomatic woman was referred to our clinic because of firs degree atrioventricular block on ECG Transthoracic echocardiography revealed a well delineated mass $(27 \mathrm{~mm} \times 29 \mathrm{~mm})$ without a stalk at the lower atrial septum, involving the upper ventricular septum (upper left panel: LA, left atrium; LV, left ventricle; RA, right atrium $\mathrm{RV}$, right ventricle). Magnetic resonance cardiac imaging with $\mathrm{Tl}$ enhancement showed a solid and homogenous mass with a smooth surface (upper right panel). Surgery revealed a tumour-like mass originating from the atrioventricular nodal region. Pathological examination demonstrated keratinous material within a multiple cystic structure of the mass that was covered by double or triple cell layers consisting of squamous cells (lower left panel). Immunohistochemical staining of this cell layer was positive for cytokeratin and carcinoembryonic antigen that represents epithelial lining (lower right panel). Thus, the mass was diagnosed as a cystic tumour of the atrioventricular node that is frequently associated with fatal atrioventricular conduction abnormalities.

Y Noiimo H Ishibashi-Ueda $M$ Yamagish myamagi@hsp.ncvc.go.jp
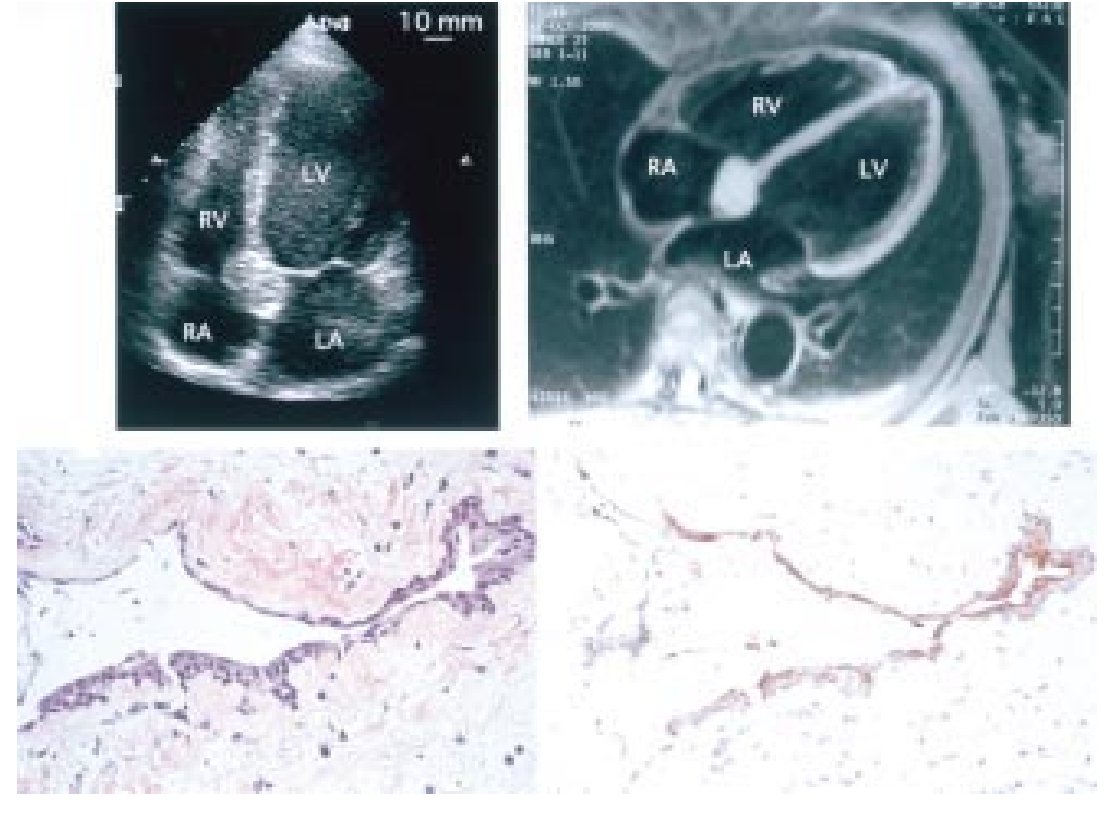